\title{
Desempenho de ovinos e respostas de pastagens de Coastcross submetidas a regimes de desfolha sob lotação contínua(1)
}

\author{
Roberta Aparecida Carnevalli(2), Sila Carneiro da Silva ${ }^{(3)}$, Carlos Augusto Brandão de Carvalho(4), \\ André Fischer Sbrissia(4), Jaílson Lara Fagundes ${ }^{(2)}$, Luiz Felipe de Moura Pinto ${ }^{(3)}$ e Carlos Guilherme Silveira Pedreira ${ }^{(3)}$
}

\begin{abstract}
Resumo - O objetivo deste estudo foi avaliar o desempenho de ovinos e as respostas de pastagens de Coastcross (Cynodon spp.) com quatro alturas de pasto $(5,10,15$ e $20 \mathrm{~cm})$, em regime de lotação contínua, no período de agosto de 1998 a abril de 1999. As alturas de pasto foram alocadas às unidades experimentais, de acordo com um delineamento de blocos completos casualizados, com quatro repetições. As variáveis analisadas foram: valor nutritivo, composição morfológica da forragem coletada por simulação de pastejo e do perfil total do pasto, taxa de acúmulo de matéria seca, e desempenho animal. Os pastos apresentaram alto valor nutritivo da forragem pastejada, em ambas as estações do ano (primavera e verão), destacando-se os pastos de $5 \mathrm{~cm}$, que apresentaram os melhores valores. As taxas de acúmulo de forragem foram maiores no verão, proporcionando, assim, maiores disponibilidades de forragem, e, conseqüentemente, desempenho animal mais elevado.
\end{abstract}

Termos para indexação: gramíneas forrageiras, valor nutritivo, alimentação animal, melhoramento de pastagens.

Pasture and animal responses of Coastcross swards grazed by sheep under continuous stocking

Abstract - Pasture and animal responses of Coastcross (Cynodon spp.) swards were evaluated under four steady state conditions (sward surface heights of 5,10,15 and $20 \mathrm{~cm}$ ), established by sheep under continuous stocking and variable stocking rate from August/98 to April/99. Sward surface heights were allocated to experimental units randomly, according to a complete randomized block design, with four replications. The variables evaluated were herbage nutritive value, morphological composition of the herbage as grazed hand sample and of the sward, herbage accumulation rate and animal performance. All swards presented high nutritive value of the grazed herbage during spring and summer, with the best values observed for the sward height of $5 \mathrm{~cm}$. Herbage accumulation rates were highest in summer, which generated higher dry matter availability and animal performance

Index terms: feed grasses, nutritive value, animal feeding, pasture improvement.

\section{Introdução}

O capim Coastcross é amplamente difundido nas fazendas do Brasil e de outros países da América do

(1) Aceito para publicação em 30 de agosto de 2000 Extraído da dissertação de mestrado, apresentada pelo primeiro autor à Escola Superior de Agricultura Luiz de Queiroz (ESALQ), Piracicaba, SP. Financiado pela FAPESP.

(2)ESALQ, Dep. de Produção Animal, Caixa Postal 9 , CEP 13418-900 Piracicaba, SP. Bolsista da CAPES. E-mail: racarnev@carpa.ciagri.usp.br,ratinhojlf@yahoo.com.br, omazzo@bol.com.br

(3)ESALQ, Dep. de Produção Animal. E-mail: scdsilva@carpa.ciagri.usp.br, cgspedre@esalq.usp.br

(4)ESALQ, Dep. de Produção Animal. Bolsista da FAPESP E-mail: sbrissia@bol.com.br
Sul e do Norte, por sua boa produção de matéria seca, excelente valor nutritivo, e, acima de tudo, sua flexibilidade de utilização, como pastagem, feno, ou silagem. No Brasil, vem sendo utilizado há muitos anos, nas diversas modalidades (Hill et al., 1998). Trata-se de um híbrido estéril, obtido do cruzamento entre a cultivar Coastal e uma introdução de bermuda proveniente do Quênia, e de alta digestibilidade. Possui colmos finos e boa relação haste/folha, mas esta relação é variável conforme o manejo imposto à planta. Suas folhas são macias, com um verde menos intenso do que o da grama-estrela. Quando lançado, o Coastcross superou as outras bermudas em produtividade, em qualidade, e pelo desempenho que ele confere ao animal. Em relação ao Coastal, foi 12\% mais digestível, apresentando maiores ganhos de peso 
quando consumido na forma de pasto (30\% superior) e de feno (40\% superior) (Burton, 1972).

Num ensaio de competição de cultivares realizado por Mislevy (1989), o Coastcross mostrou-se mais produtivo que os demais (Coastal, Tifton-44, Tifton-78, Grazer e Florico), com uma produção de $18 \mathrm{t} / \mathrm{ha} /$ ano de MS com $10,6 \%$ de proteína bruta (PB) e $63,2 \%$ de digestibilidade in vitro da matéria orgânica (DIVMO). Estudos mais abrangentes, com a presença de animais (pastejo), também foram desenvolvidos com essa cultivar. Vilela \& Alvim (1996), trabalhando com gado leiteiro, destacaram um potencial de produção de Coastcross de cerca de 20 t/ha/ano de MS de forragem de alta palatabilidade e alto valor nutritivo ( $13,9 \%$ de $\mathrm{PB}, 68 \%$ de FDN e $35 \%$ de fibra em detergente ácido (FDA)). A carga animal obtida no experimento foi de seis vacas em lactação/ha no verão e três no inverno, sem qualquer suplementação. A produção obtida foi de 20 a $25 \mathrm{t} / \mathrm{ha} / \mathrm{ano}$ de MS, ou 25 a $30 \mathrm{t} / \mathrm{ha} / \mathrm{ano}$ de feno, com $85 \%$ de MS. Carnevalli \& Silva (1999) relataram também uma produção estimada de 23 t/ha/ano de MS e taxas de acúmulo variando de 30 a $90 \mathrm{~kg} / \mathrm{ha} / \mathrm{dia}$ de MS dia durante o ano em pastos de Coastcross, em sistema rotacionado com ovinos.

Em Cuba, Milera et al. (1988) avaliaram o efeito da taxa de lotação $(2,7,3,7$ e 4,5 vacas/ha) e do período de pastejo (3,5 e 7 dias) sobre a produção de leite de vacas mestiças, em pastagens de Coastcross, sem o fornecimento de concentrado. Na média, foram obtidas produções de leite de $8,1,8,7 \mathrm{e}$ $7,8 \mathrm{~kg} / \mathrm{vaca} / \mathrm{dia}$ nas três lotações citadas, respectivamente, independentemente do período de pastejo, e produção de leite, de 8,0 e $8,6 \mathrm{~kg} / \mathrm{vaca} /$ dia nos períodos de 3,5 e 7 dias, respectivamente, independentemente da taxa de lotação empregada. Martinez et al. (1980) também testaram a necessidade de utilização de concentrado para vacas leiteiras em pastos de Coastcross, e concluíram que os animais mantidos sob dieta exclusiva dessa forrageira apresentaram produções de leite relativamente boas, o que demonstra o elevado potencial produtivo dessa gramínea. A composição química da forragem foi de $16,5 \%$ de $\mathrm{PB}$ e $51 \%$ de digestibilidade in vitro da matéria seca. Hatley et al. (1974), trabalhando com novilhos de corte, obtiveram $0,68 \mathrm{~kg} /$ novilho/dia, e $527 \mathrm{~kg} / \mathrm{ha} \mathrm{em}$ 171 dias no Coastcross, e $0,49 \mathrm{~kg} /$ novilho/dia e $372 \mathrm{~kg} / \mathrm{ha}$ em 171 dias, no Coastal.
Apesar das informações existentes, há necessidade de estudos mais abrangentes e integrados, que incluam características estruturais e morfológicas do pasto e respostas em desempenho animal obtidas em situações onde as condições de pasto (altura, índice de área foliar ou massa de forragem) foram controladas (Hodgson, 1990).

O objetivo deste trabalho foi avaliar o desempenho de ovinos e as respostas de pastagens de Coastcross com diferentes alturas, em regime de lotação contínua.

\section{Material e Métodos}

O ensaio foi conduzido na Unidade Experimental de Plantas Forrageiras (UEPF), em área do Departamento de Produção Animal da Escola Superior de Agricultura "Luiz de Queiroz", da Universidade de São Paulo, Piracicaba, São Paulo (22 42'30" latitude S; 47³8'0" longitude W; $546 \mathrm{~m}$ de altitude). O solo da região é caracterizado como Terra Roxa estruturada eutrófica, com horizonte A moderado e de textura argilosa a muito argilosa. Por ocasião da instalação do experimento, a análise de solo revelava $\mathrm{pH}\left(\mathrm{CaCl}_{2}\right)$ 5,4; $\mathrm{MO}\left(\mathrm{g} \mathrm{kg}^{-1}\right)=37,0 ; \mathrm{P}\left(\mathrm{mg} \mathrm{dm}^{-3}\right)=99$; $\mathrm{K}\left(\mathrm{cmol}_{\mathrm{c}}\right)=0,46 ; \mathrm{Ca}\left(\mathrm{cmol}_{\mathrm{c}}\right)=7,50 ; \mathrm{Mg}\left(\mathrm{cmol}_{\mathrm{c}}\right)=2,60$; $\mathrm{H}+\mathrm{Al}\left(\mathrm{cmol}_{\mathrm{c}}\right)=3,00 ; \mathrm{SB}\left(\mathrm{cmol}_{\mathrm{c}}\right)=10,60 ; \mathrm{T}\left(\mathrm{cmol}_{\mathrm{c}}\right)=$ 13,60 e $V(\%)=78 \%$. Não foram realizadas adubações de correção no momento da instalação do experimento, porque o solo apresentava alta fertilidade. A espécie utilizada foi Cynodon spp. cv. Coastcross, dada a sua versatilidade de utilização, sua boa adaptação às condições de Brasil Central, e em face do renovado interesse pela espécie, por parte da pesquisa agropecuária e do setor produtivo.

O experimento seguiu um delineamento de blocos completos casualizados, com quatro repetições. Os tratamentos corresponderam a quatro condições de pasto, caracterizadas pelas alturas de $5,10,15$ e $20 \mathrm{~cm}$, mantidas relativamente constantes durante todo o período experimental através do pastejo por ovinos, em regime de lotação contínua e carga variável. Assim, o ensaio apresentou um total de 16 unidades experimentais ( 4 blocos $\mathrm{x} 4$ unidades/ bloco) com área média de $400 \mathrm{~m}^{2}$ cada. As parcelas atingiram as alturas estimadas para os tratamentos, e passaram a ser controladas pelos animais a partir de junho de 1998. Nesse período, foram iniciadas as avaliações pré-experimentais e o período experimental efetivo foi de agosto de 1998 a abril de 1999. Durante o período experimental, a temperatura média máxima diária foi de $31,4^{\circ} \mathrm{C}$, e a mínima, de $14,4^{\circ} \mathrm{C}$. A precipitação total foi de $1.290 \mathrm{~mm}$, e a umidade relativa do ar variou entre 64,8 e $90,0 \%$. No mês de 
novembro, a precipitação foi de $26,6 \mathrm{~mm}$, enquanto a média dos últimos 80 anos foi de $128 \mathrm{~mm}$. Os dados climáticos do período experimental estão apresentados na Tabela 1 .

Durante a condução do experimento, foram realizadas seis adubações nitrogenadas com sulfato de amônio (40 kg/ha de N, em 8 de julho; $40 \mathrm{~kg} /$ ha de N, em 19 de setembro; $50 \mathrm{~kg} / \mathrm{ha}$ de $\mathrm{N}$, em 21 de outubro; $25 \mathrm{~kg} / \mathrm{ha} \mathrm{de}$ $\mathrm{N}$, em 7 de dezembro; $50 \mathrm{~kg} /$ ha de $\mathrm{N}$, em 23 de fevereiro, e $75 \mathrm{~kg} / \mathrm{ha}$ de N, em 20 de março ).

A altura do pasto foi monitorada semanalmente, por meio de 20 medições por unidade experimental, com o prato ascendente ou rising plate meter (Frame, 1981). Essa avaliação era feita duas vezes por semana, obtendo-se a altura-comprimida. Uma vez por mês, era feita a calibração da altura comprimida com a altura não-comprimida (régua), sendo este último o valor de altura utilizado como referência para o monitoramento dos tratamentos (Carnevalli, 1999). Determinada a altura média da parcela, eram adicionados ou retirados animais, caso os valores estivessem acima ou abaixo dos planejados, para cada tratamento. Os animais traçadores de ganho de peso ("testers") permaneceram o tempo todo dentro das unidades experimentais, enquanto ovinos adultos foram utilizados para a regulagem da carga e manutenção da altura de- sejada. Houve situações onde o acúmulo de matéria seca foi inferior ao necessário para o consumo dos traçadores, e os animais foram retirados com a finalidade de assegurar a manutenção das condições do pasto pré-estabelecidas. Todos os animais que eram adicionados ou retirados das unidades experimentais eram pesados, após jejum prévio de água e de alimento por 16 horas.

Mensalmente, era feita a calibração entre altura e massa da forragem, com a finalidade de relacionar a altura do pasto com a massa da forragem, e também para execução do cálculo de acúmulo de forragem, visando diminuir a necessidade de amostragens destrutivas. Com anéis de $0,25 \mathrm{~m}^{2}$ de área, eram escolhidos dois pontos dentro de cada unidade experimental, procurando sempre o ponto mais baixo e o ponto mais alto com a finalidade de obterse a maior amplitude de alturas possível. No interior do anel era medida a altura com a régua e com o prato ascendente; em seguida, a forragem era cortada no nível do solo, lavada para eliminação de resíduos de terra e fezes, secada em estufa a $65^{\circ} \mathrm{C}$ por 48 horas, e pesada. Através de análise de regressão linear, determinaram-se equações de calibração entre altura não comprimida e massa, e entre altura comprimida e massa. Essas equaçoes foram utilizadas para os cálculos de acúmulo e densidade de forragem.

Tabela 1. Dados climáticos durante o período experimental (agosto/98 a abril/99) e comparação com os dados dos últimos $80 \operatorname{anos}^{(1)}$

\begin{tabular}{lcccccc}
\hline Mês/ano & \multicolumn{3}{c}{ Temperatura $\left({ }^{\circ} \mathrm{C}\right)$} & $\begin{array}{c}\text { Chuva } \\
\text { mensal } \\
(\mathrm{mm})\end{array}$ & $\begin{array}{c}\text { Umidade } \\
\text { relativa }(\%)\end{array}$ & $\begin{array}{c}\text { Insolação } \\
\text { (h/dia) }\end{array}$ \\
\cline { 2 - 4 } & $\begin{array}{c}\text { Máxima } \\
\text { média }\end{array}$ & $\begin{array}{c}\text { Mínima } \\
\text { média }\end{array}$ & Média & & & \\
\hline Agosto/98 & 27,40 & 14,36 & 20,88 & 21,80 & 77,00 & 6,22 \\
Média (80 anos) & 26,97 & 10,77 & 18,87 & 29,49 & 61,71 & 7,85 \\
Setembro/98 & 27,65 & 15,29 & 21,47 & 63,30 & 64,78 & 5,68 \\
Média (80 anos) & 27,72 & 13,16 & 20,43 & 62,98 & 62,21 & 6,67 \\
Outubro/98 & 27,06 & 16,33 & 21,70 & 183,10 & 83,42 & 5,43 \\
Média (80 anos) & 28,56 & 15,36 & 21,96 & 110,38 & 68,82 & 6,70 \\
Novembro/98 & 30,04 & 16,45 & 23,24 & 26,60 & 76,60 & 7,79 \\
Média (80 anos) & 23,10 & 16,60 & 29,60 & 128,00 & 69,00 & 7,60 \\
Dezembro/98 & 30,01 & 19,21 & 24,61 & 200,16 & 74,30 & 6,58 \\
Média (80 anos) & 28,86 & 17,68 & 23,26 & 199,00 & 71,45 & 6,33 \\
Janeiro/99 & 30,59 & 20,41 & 25,50 & 382,80 & 87,97 & 4,91 \\
Média (81 anos) & 29,57 & 18,67 & 24,10 & 225,10 & 73,25 & 6,27 \\
Fevereiro/99 & 30,73 & 20,05 & 25,41 & 198,30 & 90,00 & 5,37 \\
Média (81 anos) & 30,22 & 19,01 & 24,60 & 188,03 & 75,49 & 6,38 \\
Março/99 & 31,42 & 18,98 & 25,20 & 210,80 & 80,74 & 7,70 \\
Média (81 anos) & 29,94 & 18,18 & 24,04 & 143,36 & 75,85 & 6,74 \\
Abril/99 & 28,52 & 15,20 & 21,86 & 89,00 & 80,70 & 8,09 \\
Média (81 anos) & 28,32 & 15,36 & 21,81 & 64,79 & 74,17 & 7,50 \\
\hline
\end{tabular}

(1)Departamento de Ciências Exatas/ESALQ/USP. 
$\mathrm{O}$ acúmulo de forragem foi obtido por meio de gaiolas de exclusão $(0,70 \times 0,70 \times 0,70 \mathrm{~m})$. Foram utilizadas três gaiolas por parcela, que, após um intervalo de 21 dias, eram retiradas, e a altura da forragem em seu interior era medida com o prato ascendente (cinco leituras por gaiola). Essa altura era, posteriormente, transformada em massa, por meio das equações de calibração. Após a medição, as gaiolas eram reancoradas em novos pontos representativos da condição das unidades experimentais, sempre tomando como referência a altura média do pasto.

$\mathrm{O}$ acúmulo de forragem foi estimado pelo método agronômico da diferença conforme a equação (Davies et al., 1993):

$\mathrm{AF}=\mathrm{MF}_{\mathrm{f}}-\mathrm{MF}_{\mathrm{i}}$

sendo: $\mathrm{AF}$, acúmulo de forragem; $\mathrm{MF}_{\mathrm{f}}$, massa de forragem, sob a gaiola, no último dia de exclusão (dia 21); e $\mathrm{MF}_{\mathrm{i}}$, massa de forragem média da parcela por ocasião da colocação das gaiolas (dia 1).

A densidade da forragem foi calculada a partir dos dados de altura média não-comprimida do pasto, e da massa de forragem correspondente (obtida com o uso das equações de calibração). O valor da massa de forragem foi dividido pela altura média, e o quociente obtido foi a densidade $(\mathrm{kg} / \mathrm{cm} /$ ha de matéria seca $(\mathrm{MS}))$

A disponibilidade de forragem foi estimada pela relação entre a taxa de acúmulo de forragem $(\mathrm{kg} / \mathrm{ha} / \mathrm{dia}$ de $\mathrm{MS}$ ) e o total de peso vivo (PV) dos animais presentes na área, no período correspondente $(\mathrm{kg} / \mathrm{ha} / \mathrm{dia}$ de $\mathrm{PV})$. A disponibilidade de forragem foi expressa em $\mathrm{kg}$ de $\mathrm{MS} / 100 \mathrm{~kg}$ de $\mathrm{PV} / \mathrm{dia}$

A coleta para análise da composição química foi efetuada segundo Sollenberger \& Cherney (1995), por meio de simulação de pastejo. As amostras foram coletadas pelo método "hand-plucking", no qual coleta-se manualmente a forragem após acurada observação do hábito de pastejo dos animais. Foram coletados aproximadamente $300 \mathrm{~g}$ de forragem fresca por unidade experimental, uma vez ao mês, durante todo o período experimental

O material coletado foi acondicionado em sacos de plástico, devidamente identificados. Após a coleta, as amostras foram levadas para uma câmara fria, com o intuito de evitar a perda de água e de nutrientes através de respiração celular. De cada amostra foi retirada uma subamostra, para fins de separação morfológica. O restante da amostra era levado para estufa a $65^{\circ} \mathrm{C}$, onde permanecia por 48 horas (tempo suficiente para o material apresentar consistência quebradiça e atingir peso constante). Após a secagem, o material era moído em moinho tipo Wiley, com peneira de $1 \mathrm{~mm}$, e encaminhado para as análises químicas no laboratório de bromatologia da ESALQ/USP. Foram realizadas as determinações dos teores de matéria seca
(MS) e matéria mineral (MM) de acordo com Silva (1990); proteína bruta (PB), pelo método da A.O.A.C., segundo Pereira \& Rossi Júnior (1996); fibra em detergente neutro (FDN); fibra em detergente ácido (FDA), e lignina, pelo método de Soest et al. (1991); e a digestibilidade in vitro da matéria orgânica (DIVMO).

A subamostra retirada a partir das amostras utilizadas para análise química foi dividida em: folhas verdes (lâminas foliares), folhas senescentes, hastes (hastes + bainhas das folhas) e material morto. Cada componente foi colocado em saquinho de papel, devidamente identificado, secado por 48 horas, e pesado. As proporções dos componentes nas amostras foram calculadas como a porcentagem do peso total.

A avaliação da estrutura do pasto foi feita por amostragens destrutivas, onde se fez a separação morfológica da forragem colhida: folhas (lâminas foliares), hastes (hastes + bainhas) e material morto. Foram utilizados dois quadrados de $0,25 \mathrm{~m}$ de lado por parcela, e toda a forragem colhida no interior de cada quadrado foi cortada ao nível do solo.

Para avaliar o desempenho animal foram utilizados ovinos deslanados em crescimento, mestiços, com grau de sangue variável da raça Santa Inês e idade média de nove meses e peso médio de $25 \mathrm{~kg}$ no início do período experimental. Estes foram substituídos quando completaram um ano de vida. Os novos animais tinham idade média de 4 meses, com lotes de peso médio de 12 e $18 \mathrm{~kg}$, e foram alocados às unidades experimentais em novembro de 1998. Os animais foram separados em grupos, segundo raça, sexo, idade e peso, seguindo essa ordem de importância. Os pares traçadores ("testers"), dois animais por unidade experimental, somavam o mesmo peso em todas as unidades experimentais dentro do bloco. A distribuição dos grupos para os blocos, e dos pares para as unidades experimentais, foi aleatória

Foi avaliado o ganho de peso vivo por animal e por área, e a capacidade de carga animal. As pesagens foram mensais, sempre no mesmo horário do dia, e após um jejum de água e alimento de 16 horas. Os animais eram presos à tarde, e pesados na manhã do dia seguinte. De acordo com Matches (1970), o jejum evita possíveis variações diárias de peso, como resultado do enchimento gastrintestinal, oferecendo maior segurança e confiabilidade nos resultados obtidos. Os animais usados para regular a carga destinada a manter as alturas de pasto eram pesados na entrada e na saída, também após jejum. Todos os animais foram everminados a cada 30 dias, tomando-se por base uma contagem mínima de 500 ovos por grama de fezes. 
O consumo de forragem foi estimado por meio de cálculos feitos a partir do peso do animal, ganho de peso vivo, energia metabólica do alimento, e a exigência nutricional da categoria animal, segundo Le Du \& Penning (1982). As equações utilizadas para esta estimativa foram as seguintes:

$\mathrm{ED}=0,1233 \mathrm{~PB}+0,1705 \mathrm{DMO}+0,285$

$\mathrm{Ema}=0,815 \mathrm{ED}$

Emc $=$ antilog $[1,11 \log 10(\mathrm{GPI})+(0,004 \mathrm{PV})-2,1]$ 0,0435 Ema

$\mathrm{Emm}=1,4+0,15 \mathrm{PV}$

Consumo $=(\mathrm{Emc}+\mathrm{Emm}) / \mathrm{Ema}$,

sendo: $\mathrm{ED}$, energia digestível; $\mathrm{PB}$, proteína bruta; $\mathrm{DMO}$, digestibilidade da matéria orgânica; Ema, energia metabolizável do alimento; Emc, energia metabolizável de crescimento; GPI, ganho de peso individual; PV, peso vivo; Emm, energia metabolizável de manutenção.

\section{Resultados e Discussão}

As produções de matéria seca de Coastcross obtidas no período experimental corresponderam a $20.630,19.270,17.720$ e $17.680 \mathrm{~kg} / \mathrm{ha}$ de MS para as alturas do pasto de $5,10,15 \mathrm{e} 20 \mathrm{~cm}$, respectivamente. Na primavera, as taxas de acúmulo de matéria seca de forragem variaram de 60 a $72 \mathrm{~kg} / \mathrm{ha} / \mathrm{dia}$ de MS e no verão, a variação foi de 85 a $100 \mathrm{~kg} / \mathrm{ha} / \mathrm{dia}$ de MS (Tabelas 2 e 3). As taxas de acúmulo no verão foram $40 \%$ superiores às da primavera, aumento, este, justificado pela maior disponibilidade de fatores de crescimento existentes naquela época do ano (Tabela 1). Carnevalli \& Silva (1999), trabalhando com Coastcross pastejado por ovinos, observaram uma amplitude anual das taxas de acúmulo de matéria seca de 30 a $90 \mathrm{~kg} / \mathrm{ha} / \mathrm{dia}$ de MS e uma produção anual média estimada em 23 t/ha de MS. Já Vilela \& Alvim (1996) obtiveram 20 t/ha/ano de MS de Coastcross submetido ao pastejo por vacas leiteiras.

Pastos mantidos baixos apresentaram as maiores produções de matéria seca, apesar de não terem sido observadas diferenças significativas entre as taxas de acúmulo de forragem. Possivelmente estas não foram detectadas, devido à metodologia utilizada para medição do acúmulo de forragem. A utilização de gaiolas de exclusão promove uma superestimativa do acúmulo de forragem dos pastos mais baixos e uma subestimativa do acúmulo dos pastos mais altos (Frame, 1981). Pastos mantidos continuamente bai- xos apresentam alta quantidade de perfilhos pequenos e baixa interceptação luminosa. Quando isolados da ação do animal, os perfilhos crescem em tamanho, sem, contudo, haver uma redução proporcional na densidade de perfilhos durante o período de avaliação; ou seja, há um intervalo de tempo entre o sinal de compensação e a morte dos perfilhos para um novo equilíbrio. Durante esse período, portanto, estimativas de acúmulo são inflacionadas. Nos pastos mais altos, a interceptação de luz encontra-se mais próxima de valores elevados, diferentemente de pastos mais baixos. Assim, para o mesmo período de acúmulo (21 dias), chega-se à interceptação de $95 \%$ de luz mais cedo, com redução drástica na velocidade de acúmulo, obtendo-se, como resultado, valores semelhantes de taxa média de acúmulo, nos dois casos.

Além do maior acúmulo de matéria seca, a forragem consumida nos pastos com altura de $5 \mathrm{~cm}$ apresentou melhor valor nutritivo que os demais tratamentos. O teor de proteína bruta atingiu valores acima de $20 \%$, enquanto as outras alturas apresentaram teores ao redor de $16 \%$ na primavera, que, posteriormente, elevaram-se para $18 \%$ no verão (Tabelas 2 e 3). Em pastagens de Coastcross foram encontrados teores de proteína bruta variando entre 16 e $23 \%$ (Vilela \& Alvim, 1996). Alvim et al. (1996) detectaram diferenças no teor de proteína entre épocas do ano, com valores que variaram de $13 \%$ a $19 \%$ no período das águas (primavera/verão) e de $11 \%$ a $16 \%$ no período da seca (outono/inverno).

Uma menor proporção de fibra também foi constatada na forragem proveniente dos pastos com altura de $5 \mathrm{~cm}(\mathrm{P}<0,05)$. Esta apresentou $62 \%$ de FDN, enquanto a forragem proveniente de pastos mantidos mais altos variou de 65 a $67 \%$. Alvim et al. (1996) encontraram teores de FDN de Coastcross variando entre $63 \%$ e $70 \%$ na época das águas, e de $64 \%$ a $74 \%$ na época seca. O mesmo comportamento foi observado nos teores de FDA, com a forragem oriunda de pastos de $5 \mathrm{~cm}$ apresentando $25 \%$ de FDA, enquanto a forragem dos demais apresentou teores ao redor de $28 \%(\mathrm{P}<0,05)$. Os teores de FDA não sofreram alteração com a época do ano. Já os teores de lignina variaram ao longo do ano, sendo observada grande redução da primavera ao verão. Na primavera, os valores flutuaram entre $6 \%$ e $7 \%$ 
de lignina, e no verão passaram a variar entre $3 \%$ e 4\%. Vilela \& Alvim (1996) encontraram valores de FDN que variaram de $64 \%$ a $71 \%$ em Coastcross pastejado por vacas leiteiras durante todo o ano.

Como conseqüência do melhor valor nutritivo, a forragem proveniente de pastos de $5 \mathrm{~cm}$ apresentou os maiores valores de DIVMO na primavera, cerca de $80 \%(\mathrm{P}<0,05)$, mantendo essa tendência no verão, porém sem diferença significativa. Nas demais alturas de pasto, a digestibilidade foi decrescente com o aumento em altura, com exceção da altura de $15 \mathrm{~cm}$ na primavera, quando a digestibilidade do capim foi de $68 \%$, fato, este, justificado pela maior porcentagem de hastes, material morto e folhas senescentes, e menor porcentagem de folhas presentes na composição da forragem pastejada (Tabela 2). Vilela \& Alvim (1996) encontraram valores de DIVMS que variaram de $61 \%$ a $66 \%$ em Coastcross. O maior valor nutritivo e a maior digestibilidade da forragem proveniente dos pastos de $5 \mathrm{~cm}$ foram decorrentes de uma maior porcentagem de folhas. A composição da forragem pastejada foi reflexo da estrutura dos pastos. Nota-se que nas alturas mais baixas houve tendência de maior porcentagem de folhas e menor porcentagem de material morto em relação a alturas mais elevadas, tanto na primavera como no verão.

O comportamento das variáveis estudadas foi semelhante tanto na primavera como no verão. Entretanto, a amplitude de variação nos valores foi maior na primavera. No verão, praticamente não foram observadas diferenças significativas.

A capacidade de carga animal obtida no experimento foi decrescente com o aumento da altura do pasto, e nos pastos mantidos a $5 \mathrm{~cm}$ foram observados valores de aproximadamente 1.500 e $1.860 \mathrm{~kg} / \mathrm{ha} / \mathrm{dia}$ de PV na primavera e verão, respectivamente.

Tabela 2. Desempenho de ovinos e comportamento de pastagens de Coastcross mantidas sob diferentes alturas de pastos durante o período da primavera da estação de crescimento de 1998/1999(1).

\begin{tabular}{|c|c|c|c|c|c|}
\hline \multirow[t]{2}{*}{ Variável } & \multicolumn{5}{|c|}{ Altura do pasto $(\mathrm{cm})$} \\
\hline & 5 & 10 & 15 & 20 & $\mathrm{EPM}^{(2)}$ \\
\hline \multicolumn{6}{|l|}{ Respostas da pastagem e dos animais } \\
\hline Taxa de acúmulo (kg/ha/dia de MS) & $71,9 \mathrm{a}$ & $64,9 \mathrm{a}$ & $60,4 a$ & $63,9 \mathrm{a}$ & 10,1 \\
\hline Capacidade de carga (kg/ha/dia de PV) & $1507 \mathrm{a}$ & $1201 \mathrm{ab}$ & $1300 \mathrm{a}$ & $854 b$ & 115,9 \\
\hline Disponibilidade de forragem (\% PV) & $5,2 \mathrm{a}$ & $5,3 \mathrm{a}$ & $4,9 \mathrm{a}$ & $7,0 \mathrm{a}$ & 1,0 \\
\hline Ganho por animal (g/animal/dia) & $1,3 \mathrm{a}$ & $11,8 \mathrm{a}$ & $16,5 \mathrm{a}$ & $27,4 \mathrm{a}$ & 7,2 \\
\hline Ganho por área $(\mathrm{kg} / \mathrm{ha} / \mathrm{dia})$ & $0,6 \mathrm{a}$ & $1,1 \mathrm{a}$ & $1,3 \mathrm{a}$ & $1,6 \mathrm{a}$ & 0,5 \\
\hline Consumo de forragem (g/animal/dia de MS) & $119 b$ & $371 \mathrm{ab}$ & $248 \mathrm{ab}$ & $422 \mathrm{a}$ & 81,2 \\
\hline \multicolumn{6}{|l|}{ Estrutura do pasto } \\
\hline Folhas $(\%)$ & $20,6 \mathrm{a}$ & $20,6 \mathrm{a}$ & $17,7 \mathrm{a}$ & $16,8 \mathrm{a}$ & 1,3 \\
\hline Hastes (\%) & $43,1 \mathrm{a}$ & $44,4 \mathrm{a}$ & $42,3 \mathrm{a}$ & $39,7 \mathrm{a}$ & 2,1 \\
\hline Material morto (\%) & $36,2 b$ & $35,7 b$ & $40,0 \mathrm{ab}$ & $43,4 \mathrm{a}$ & 2,3 \\
\hline Densidade de forragem $(\mathrm{kg} / \mathrm{cm} / \mathrm{ha}$ de $\mathrm{MS})$ & $372 \mathrm{a}$ & $287 \mathrm{~b}$ & $250 \mathrm{c}$ & $233 \mathrm{c}$ & 6,3 \\
\hline \multicolumn{6}{|l|}{ Valor nutritivo da forragem pastejada } \\
\hline Proteína bruta (\%) & 20,0a & $16,9 \mathrm{ab}$ & $16,5 \mathrm{ab}$ & $15,7 \mathrm{~b}$ & 0,8 \\
\hline $\operatorname{FDN}(\%)^{(3)}$ & $62,3 \mathrm{c}$ & $65,0 \mathrm{~b}$ & $66,0 \mathrm{ab}$ & $67,1 \mathrm{a}$ & 0,7 \\
\hline $\operatorname{FDA}(\%)^{(4)}$ & $25,0 \mathrm{c}$ & $27,1 b$ & $27,8 \mathrm{ab}$ & $29,1 \mathrm{a}$ & 0,6 \\
\hline Lignina (\%) & $6,1 \mathrm{a}$ & $6,8 \mathrm{a}$ & $6,5 \mathrm{a}$ & $6,2 \mathrm{a}$ & 0,6 \\
\hline $\operatorname{DIVMO}(\%)^{(5)}$ & $80,6 \mathrm{a}$ & $75,9 \mathrm{ab}$ & $68,6 \mathrm{~b}$ & $75,4 \mathrm{ab}$ & 3,7 \\
\hline \multicolumn{6}{|l|}{ Composição da forragem pastejada } \\
\hline Folhas (\%) & $60,5 \mathrm{a}$ & $55,0 \mathrm{a}$ & $51,6 \mathrm{a}$ & $54,9 \mathrm{a}$ & 3,6 \\
\hline Hastes $(\%)$ & $23,9 \mathrm{a}$ & $25,3 \mathrm{a}$ & $30,0 \mathrm{a}$ & $23,3 \mathrm{a}$ & 4,3 \\
\hline Material morto (\%) & $12,6 b$ & $16,0 \mathrm{ab}$ & $16,5 \mathrm{ab}$ & $19,5 \mathrm{a}$ & 2,0 \\
\hline Folhas senescentes $(\%)$ & $3,9 \mathrm{a}$ & $3,1 \mathrm{a}$ & $3,8 \mathrm{a}$ & $2,0 \mathrm{a}$ & 0,6 \\
\hline
\end{tabular}

${ }^{(1)}$ Em cada coluna, médias seguidas da mesma letra não diferem entre si pelo teste do LSMEANS - SAS a 5\% de probabilidade. ${ }^{(2)}$ Erro-padrão da média. ${ }^{(3)}$ Fibra em detergente neutro. ${ }^{(4)}$ Fibra em detergente ácido. ${ }^{(5)}$ Digestibilidade in vitro da matéria orgânica. 
Em todas as alturas de pasto houve aumento da capacidade de carga da primavera para o verão, conseqüência das maiores taxas de acúmulo de matéria seca naquele período. A variável resultante da combinação entre acúmulo diário e capacidade de carga animal é a disponibilidade de forragem. Não houve diferença entre alturas do pasto para esta variável, nas duas estações do ano $(\mathrm{P}>0,05)$. Existiu, contudo, tendência de aumento na disponibilidade média de forragem com o aumento da altura do pasto e com a mudança de estação do ano. Apesar da ausência de diferenças entre alturas do pasto, a disponibilidade de forragem afetou o desempenho animal. Foram obtidos ganhos de peso da ordem de 1,3 g/animal/dia nos pastos de $5 \mathrm{~cm}$ a $27 \mathrm{~g} / \mathrm{animal} /$ dia nos pastos de $20 \mathrm{~cm}$ na primavera, e de 40 a $54 \mathrm{~g} /$ animal/dia no verão. $\mathrm{O}$ ganho de peso por área variou de $0,6 \mathrm{a}$ $1,6 \mathrm{~kg} / \mathrm{ha} /$ dia de PV na primavera, e de 2,4 a
$4,78 \mathrm{~kg} / \mathrm{ha} /$ dia de PV no verão. Hatley et al. (1974), trabalhando com novilhos de corte, obtiveram ganho individual de $680 \mathrm{~g} /$ novilho/dia, e ganho por área de $3,1 \mathrm{~kg} / \mathrm{ha} /$ dia de PV em 171 dias de avaliação.

A diferença de desempenho animal observada entre as estações do ano pode ter sido causada pela variação nas taxas de acúmulo de forragem. Para manter a altura e estrutura do pasto foi necessário certo número de animais em cada unidade experimental. Na primavera, o acúmulo diário de forragem foi relativamente baixo, mas o alongamento e lignificação das hastes foram acelerados, devido ao grande florescimento ocorrido naquela época do ano (Carvalho, 2000). Assim, para manter o controle do pasto, foi necessário um número de animais além daquele que o acúmulo de forragem diário pudesse sustentar com disponibilidade de forragem e consumo satisfatórios. Com isso, na primavera, a carga

Tabela 3. Respostas de animais e das pastagens de Coastcross mantidas sob quatro alturas de pasto (cm) durante o período do verão na fase de crescimento de 1998/1999(1).

\begin{tabular}{|c|c|c|c|c|c|}
\hline \multirow[t]{2}{*}{ Variável } & \multicolumn{5}{|c|}{ Altura do pasto $(\mathrm{cm})$} \\
\hline & 5 & 10 & 15 & 20 & $\mathrm{EPM}^{(2)}$ \\
\hline \multicolumn{6}{|l|}{ Respostas da pastagem e dos animais } \\
\hline Taxa de acúmulo (kg/ha/dia de MS) & $97,3 \mathrm{a}$ & $99,9 \mathrm{a}$ & $93,3 \mathrm{a}$ & $84,6 a$ & 10,4 \\
\hline Capacidade de carga (kg/ha/dia de PV) & $1859 a$ & $1676 a$ & $1414 \mathrm{a}$ & $1483 a$ & 168,0 \\
\hline Disponibilidade de forragem (\% PV) & $5,7 \mathrm{a}$ & $6,3 \mathrm{a}$ & $7,4 \mathrm{a}$ & $6,4 a$ & 0,8 \\
\hline Ganho por animal (g/animal) & $45,3 \mathrm{a}$ & $39,3 \mathrm{a}$ & $49,5 \mathrm{a}$ & $54,0 \mathrm{a}$ & 7,5 \\
\hline Ganho por área (kg/ha/dia) & $4,7 \mathrm{a}$ & $3,6 a$ & $3,6 a$ & $2,4 \mathrm{a}$ & 1,1 \\
\hline Consumo de forragem (g/animal/dia de MS) & $351 \mathrm{a}$ & $397 \mathrm{a}$ & $411 \mathrm{a}$ & $421 \mathrm{a}$ & 38,9 \\
\hline \multicolumn{6}{|l|}{ Estrutura do pasto } \\
\hline Folhas $(\%)$ & $20,4 \mathrm{a}$ & $21,2 \mathrm{a}$ & $20,1 \mathrm{a}$ & $16,7 b$ & 1,0 \\
\hline Hastes (\%) & $46,4 \mathrm{a}$ & $42,8 \mathrm{a}$ & $41,7 \mathrm{a}$ & $42,4 \mathrm{a}$ & 2,4 \\
\hline Material morto (\%) & $33,1 \mathrm{a}$ & $35,9 \mathrm{a}$ & $38,2 \mathrm{a}$ & $40,9 \mathrm{a}$ & 3,3 \\
\hline Densidade de forragem $(\mathrm{kg} / \mathrm{cm} / \mathrm{ha}$ de $\mathrm{MS})$ & $339 \mathrm{a}$ & $283 \mathrm{~b}$ & $268 \mathrm{c}$ & $256 \mathrm{~d}$ & 1,4 \\
\hline \multicolumn{6}{|l|}{ Valor nutritivo da forragem pastejada } \\
\hline Proteína bruta (\%) & $21,2 \mathrm{a}$ & $18,4 b$ & $18,2 b$ & $16,4 \mathrm{c}$ & 0,5 \\
\hline FDN $(\%)^{(3)}$ & $61,8 b$ & $66,4 \mathrm{a}$ & $65,7 \mathrm{a}$ & $67,3 \mathrm{a}$ & 0,6 \\
\hline FDA $(\%)^{(4)}$ & $25,1 \mathrm{c}$ & $27,6 \mathrm{~b}$ & $27,5 b$ & $28,5 \mathrm{a}$ & 0,3 \\
\hline Lignina $(\%)$ & $3,4 \mathrm{ab}$ & $3,8 \mathrm{ab}$ & $2,9 b$ & $4,4 a$ & 0,4 \\
\hline $\operatorname{DIVMO}(\%)^{(5)}$ & $80,2 \mathrm{a}$ & $78,7 \mathrm{a}$ & $79,7 \mathrm{a}$ & $79,4 \mathrm{a}$ & 1,2 \\
\hline \multicolumn{6}{|l|}{ Composição da forragem pastejada } \\
\hline Folhas (\%) & $66,9 a$ & $66,1 \mathrm{a}$ & $64,0 \mathrm{a}$ & $67,0 \mathrm{a}$ & 2,1 \\
\hline Hastes (\%) & $18,1 \mathrm{a}$ & $21,7 \mathrm{a}$ & $23,0 \mathrm{a}$ & $22,4 \mathrm{a}$ & 2,3 \\
\hline Material morto (\%) & $11,1 \mathrm{a}$ & $9,0 \mathrm{a}$ & $9,2 \mathrm{a}$ & $8,6 \mathrm{a}$ & 1,0 \\
\hline Folhas senescentes $(\%)$ & $3,1 \mathrm{a}$ & $3,7 \mathrm{a}$ & $1,9 \mathrm{a}$ & $2,2 \mathrm{a}$ & 1,2 \\
\hline
\end{tabular}

${ }^{(1)}$ Em cada coluna, médias seguidas da mesma letra não diferem entre si pelo teste do LSMEANS - SAS a 5\% de probabilidade. (2)Erro-padrão da média ${ }^{(3)}$ Fibra em detergente neutro. ${ }^{(4)}$ Fibra em detergente ácido. ${ }^{(5)}$ Digestibilidade in vitro da matéria orgânica. 
animal foi alta, mas o desempenho individual e por área foram baixos. No verão, o acúmulo diário de forragem aumentou consideravelmente, e o maior reflexo observado foi sobre os valores de ganho individual e não no número de animais na área, pois os animais tiveram oportunidade de aumentar o seu consumo individual, e, conseqüentemente, o desempenho. Este fato pode ser ilustrado pelos valores de estimativas de consumo apresentado nas Tabelas 2 e 3 . Em média, houve aumento do consumo individual da primavera para o verão. Contudo, o consumo não ultrapassou 422 g/animal/dia. Segundo Hodgson (1984), o consumo dos animais em pastagens normalmente aproxima-se de um valor máximo em níveis de disponibilidade três a quatro vezes superiores à ingestão de matéria seca, mas apresenta redução acentuada quando a disponibilidade é inferior a duas vezes o consumo (Hodgson, 1984). Considerando que o consumo potencial de um cordeiro de peso médio de $20 \mathrm{~kg}$ é de $600 \mathrm{~g} / \mathrm{animal} / \mathrm{dia}$ (3\% do peso vivo (PV)), a disponibilidade de forragem para atingir consumo máximo deveria estar entre $9 \%$ e $12 \%$ PV, de acordo com Hodgson (1984). Para Tifton-85, uma disponibilidade de forragem de $7 \%$ do PV proporcionou um consumo maior que o obtido em Coastcross, dada a maior densidade de forragem (Carnevalli, 1999). O Coastcross apresentou densidade de forragem que variou de 230 a $370 \mathrm{~kg} / \mathrm{cm} / \mathrm{ha}$ de MS, na primavera, e de 250 a $340 \mathrm{~kg} / \mathrm{cm} / \mathrm{ha}$ de MS, no verão. Carnevalli (1999) relatou valores para Tifton-85 que variaram de 370 a $610 \mathrm{~kg} / \mathrm{cm} / \mathrm{ha}$ de MS na primavera, e de 320 a $420 \mathrm{~kg} / \mathrm{cm} / \mathrm{ha}$ de MS no verão.

No período total de experimento, foi obtido o número de dias de pastejo referente a cada altura de pasto estudada. Considerando o período total do experimento de 273 dias, os animais permaneceram $87 \%$ do tempo dentro dos pastos de $5 \mathrm{~cm}$ (238 dias), $85 \%$ nos pastos de $10 \mathrm{~cm}$ (231 dias), $79 \%$ nos pastos de $15 \mathrm{~cm}$ ( 215 dias), e $83 \%$ nos pastos de $20 \mathrm{~cm}$ ( 227 dias). Contudo, não houve diferença estatística $(\mathrm{P}>0,05)$, apesar do menor tempo de permanência dos animais nos pastos de $15 \mathrm{~cm}$.

\section{Conclusões}

1. O Cynodon spp. cv. Coastcross apresenta alto valor nutritivo quando utilizado em pastejo contínuo, independentemente da altura em que é manejado.
2. O valor nutritivo do Cynodon é conseqüência da sua composição morfológica, ou, mais especificamente, da proporção de folhas do dossel.

3. A disponibilidade de forragem deste capim aumenta com o aumento da altura do pasto, e os pastos mantidos a $5 \mathrm{~cm}$ de altura proporcionam consumo limitado.

4. Maiores níveis de desempenho individual dos ovinos são obtidos com maiores disponibilidades de forragem atingidas em decorrência do aumento das taxas de acúmulo de matéria seca.

5. Pastos mantidos mais baixos apresentam maior capacidade de carga animal, e, conseqüentemente, melhor nível de utilização dos pastos.

\section{Agradecimentos}

Ao GEPF (Grupo de Estudos de Plantas Forrageiras), pelo auxílio nos trabalhos de campo; à FAPESP e à CAPES, pelo financiamento do projeto.

\section{Referências}

ALVIM, M. J.; BOTREL, M. A.; PASSOS, L. P.; BRESSAN, M.; VILELA, D. Efeito da freqüência de cortes e do nível de nitrogênio sobre a produção e qualidade da matéria seca do Coastcross. In: WORKSHOP SOBRE O POTENCIAL FORRAGEIRO DO GENERO CYNODON, 1996, Juiz de Fora. Anais... Juiz de Fora : Embrapa-CNPGL. 1996. p. 45-56.

BURTON, G. W. Registration of coastcross-1 bermudagrass. Crop Science, Madison, v. 12, p. 125, 1972.

CARNEVALLI, R. A. Desempenho de ovinos e respostas de pastagens de Cynodon spp. submetidos a regimes de desfolha sob lotação contínua. Piracicaba : ESALQ, 1999. 90 p. Dissertação de Mestrado.

CARNEVALLI, R. A.; SILVA, S. C. da. Validação de técnicas experimentais para avaliação de características agronômicas e ecológicas de pastagens de Cynodon dactylon cv. Coastcross-1. Scientia Agricola, Piracicaba, v. 56, n. 2, p. 489-499, abr.jun. 1999.

CARVAlHO, C. A. B. Padrões demográficos de perfilhamento e acúmulo de forragem em pastagens de Cynodon spp. manejadas em quatro intensidades de pastejo. Piracicaba : ESALQ, 2000. 96 p. Dissertação de Mestrado. 
DAVIES, D. A.; FUTHERGILL, M.; MORGAM, C. T. Assessment of contrasting perennial ryegrasses with and white clover, under continuous stocking in the uplands. 5 Herbage production, quality and intake in years 4-6. Grass and Forage Science, Oxford, v. 48, n. 3, p. 213-222, Sept 1993.

FRAME, J. Herbage mass. In: HODGSON, J.; BAKER, R. D.; DAVIES, A.; LAIDLAW, A. S.; LEAVER, J. D (Ed.). Sward measurement handbook. Hurley : British Grassland Society, 1981. p. 39-67.

HATLEY, P. R.; CHAPMAM, H.; MONSON, W. G.; MARCHANT, W. H.; McCARMICK, W. C. Coastcross bermudagrass, coastal bermudagrass and Pensacola bahiagrass as summer pasture for steers. Journal of Animal Science, Champaign, v. 38, n. 3, p. 490-495, 1974

HILL, G. M.; GATES, R. N.; WEST, J. W.; MANDEBVU, P. Pesquisa com capim bermuda cv. 'Tifton-85' em ensaios de pastejo e de digestibilidade de feno com bovinos. In: SIMPÓSIO SOBRE MANEJO DE PASTAGEM, 15. 1998, Piracicaba. Anais... Piracicaba : FEALQ, 1998. p. 7-22.

HODGSON, J. Herbage production and utilization. In GRAZING management: science into practice. New York : J. Wiley, 1990. 203 p.

HODGSON, J. Swards conditions, herbage allowance and animal production: an evaluation of research results. New Zealand Society of Animal Production Proceedings, Hamilton, v. 44, p. 99-104, 1984

LE DU, Y. L. P.; PENNING, P. D. Animal based techniques for estimating herbage intake. In: LEAVER, J. D. Herbage intake handbook. Maidenhead : British Grassland Society, 1982. p. 37-76.

MARTINEZ, R. O.; RUIZ, R.; HERRERA, R. Milk production of cows grazing Coastcross-1 bermudagrass
(Cynodon dactylon). 1. Different concentrate supplementation levels. Cuban Journal of Agricultural Science, Havana, v. 14, n. 2, p. 225-232, 1980.

MATCHES, A. G. Pasture research methods 1. In: NATIONAL CONFERENCE ON FORAGE QUALITY EVALUATION AND UTILIZATION, 1969, Lincoln.

Proceedings... Lincoln : [s.n.], 1970. p. 1-32

MILERA, M.; GARCIA-TRUJILLO, R.; MENCHACA, M. Efecto de la carga y la estancia sobre la producción de leche en bermuda cruzada 1. 11. Análisis de los sistemas destacados con un nivel medio de N. Pastos y Forrajes, Havana, v. 11, n. 2, p. 165-170, 1988.

MISLEVY, P. Florona stargrass. Gainsville : University of Florida, 1989. 15 p. (Circular, 361).

PEREIRA, J. R. A.; ROSSI JÚNIOR, P. Manual prático de avaliação nutricional de alimentos. Piracicaba : FEALQ, 1996. $34 \mathrm{p}$.

SILVA, D. J. Análise de alimentos: métodos químicos e biológicos. Viçosa : UFV, 1990. $165 \mathrm{p}$

SOEST, P. J. van; ROBERTSON, J. B.; LEWIS, B. A. Methods for dietary fiber, neutral detergent fiber and nonstarch polysaccharides in relation to animal nutrition. Journal of Dairy Science, Savoy, v. 74, p. 3583-3597, 1991.

SOLLENBERGER, L. E.; CHERNEY, D. J. R. Evaluating forage production and quality. In: THE SCIENCE of grassland agriculture. Ames : Iowa State University Press, 1995. p. 97-110

VILELA, D.; ALVIM, M. J. Produção de leite em pastagem de Cynodon dactylon cv. Coastcross. In: WORKSHOP SOBRE O POTENCIAL FORRAGEIRO DO GÊNERO CYNODON, 1996, Juiz de Fora. Anais.. Juiz de Fora : Embrapa-CNPGL, 1996. p. 77-92. 